\title{
Operations mechanism of postponement strategy for service-oriented manufacturing
}

\author{
Jianqiang Luo ${ }^{1} \cdot$ Qinhong Zhang ${ }^{1}$
}

Received: 8 December 2016 / Accepted: 20 November 2018 / Published online: 29 November 2018

(C) The Author(s) 2018

\begin{abstract}
With the rapid growth of individualized customer demands, manufacturers are supposed to pay more attention to the interaction between service and product. In this context, the concept called service-oriented manufacturing (SOM) has been promoted. Postponement strategy, while has already been widely studied in manufacturing systems, still lacks being well understood about its operations mechanism for SOM. Therefore, the purpose of this paper is to provide a further insight into an operations mechanism in which SOM can be driven by postponement strategy. Firstly, by analyzing the characteristics of postponement strategy and SOM, the hypothesis that postponement strategy can support SOM is theoretically approved. Then, to better reveal its operations mechanism, an innovative model is constructed. In this model, non-differentiated and differentiated products are compared, service time is introduced as a sensitive factor, and an approach incorporating customer satisfaction is proposed. Taking advantages of these innovation points, the customer order fulfilling time can be easily analyzed in the SOM system applied postponement strategy. The research results show that the cost of customer interaction could be reduced through the adjustment activities before customer order decoupling point, and the degree of product customization could be increased by interactive activities after customer order decoupling point. Both of them would enable manufacturers to better respond to customized demands.
\end{abstract}

Keywords Service-oriented manufacturing $\cdot$ Postponement strategy $\cdot$ Customer order decoupling point $\cdot$ Service time

\section{Introduction}

China's industrial structure has been transforming from being mainly directed by traditional manufacturing industries into being increasingly dominated by service based on manufacturing. This phenomenon is mostly caused by market globalization and continually strict service demands. In this context, most of manufacturers bear more and more competitive pressure and, necessarily, are seeking new business strategies that can quickly respond to customized demands. Currently, postponement strategy is a kind of popular and key operations management method in the world [1]. The basic idea of postponement strategy is originally keeping parts in their standard form before customer order decoupling point, when specific demands are known, the standard parts are customized according to customer requirements, whereby manufacturers can meet various and unique

Jianqiang Luo

luojianqiang@ujs.edu.cn

1 Department of Industrial Engineering, School of Management, Jiangsu University, Zhenjiang 212013, China customer demands. Furthermore, by pushing the inventory of production upstream into less costly stage, postponement strategy can also help manufacturers to save lead time, improve service level, achieve the goal of cost reductions, and provide various offerings [2].

However, adopting postponement strategy in the context of product-dominated logic can easily lead to physical product homogenization and cutthroat competition among manufacturers [3]. As for customers, when they purchase a product, their attention mostly centered on product functionality and the purpose of occupying the product is secondary. For example, the main motivation of customers buying cups is to use them for drinking instead of just owing them. Manufacturing organizations who have already implemented postponement strategy were preparing to adopt service strategies as a new source to gain competitive advantages, exactly as the practices of many multinational manufacturing companies, such as IBM, GM, and Intel, showing how crucial service strategies are for their businesses [3]. This new type of advanced manufacturing mode is termed as service-oriented manufacturing (SOM) paradigm [4].

In consideration of typical interaction and integration between services and manufacturing industries in China's industry, the statement that services intensively relying on physical 
products can effectively solve heterogeneous customer requirements has mostly received recognition and been accepted by academia and industry. SOM is a theoretical guidance for Chinese manufacturing companies to transform their manufacturing business into service sector, as well as directs them to provide an integrated solution for customers $[5,6]$. Thus, it is necessary for us to better understand how postponement strategy applied into SOM system to fit its characteristics. There are three questions should be asked if a manufacturing company was interested in introducing postponement strategy in SOM system: (1) what is the role postponement strategy plays in an SOM system? (2) How to theoretically explain the postponement strategy being applied in SOM system? And (3) what is the process for postponement strategy being implemented into SOM system?

To answer these questions, the remainders of this paper are organized as follows. In Section 2, some related literature of postponement strategy and SOM is reviewed; on this basis, research motivations are outlined. In Section 3, the role of postponement strategy in SOM system is stressed. In Section 4, a game model is built to analyze the operations mechanism of postponement being implemented in SOM system. A model considering service time is established and its operations mechanism is explained in Section 5. Conclusions, research limitations, and scope for further research are presented in the final section.

\section{Literature review}

\subsection{Postponement strategy}

According to Van (2001), in a manufacturing system, postponement strategy aims not to delay product customization activities until customer demands are revealed [7]. The initial motivation of implementing postponement strategy is to avoid, before obtaining accurate and personalized customer demand information, uncertainty in manufacturing operations and reduce overall operation costs. Therefore, manufacturing companies may delay customization activities as far as possible [7]. Postponement strategy has been successfully applied in different industries [8], such as Dell computer, IKEA's "Do it Yourself," Amazon's "Build your own ring," and Nike's "Design your shoes." Currently, the postponement strategy is mainly introduced in mass customization and supply chain management activities, and some literature predicted that postponement strategy would gain more attention in the twentyfirst century, because it has direct impacts on companies' competitiveness and organizational performance $[9,10]$. In general, postponement strategy has substantial benefits for a manufacturing system on the aspects of time, quality, and cost. Graman and Magazine (2002) found that while postponement strategy leads to an inventory reduction, service level remains unchanged [11]. In order to maximize the efficiency of postponement strategy, manufacturing companies have been showing increasing interest in adopting a kind of technology called customer order decoupling point (CODP), which refers to "the point of product differentiation point." CODP is an important input for a manufacturing operations strategy designing. In addition, CODP is defined as the point which separates decisions relying on forecast from decisions based on detailed product order in the value-adding chain. In other words, CODP divides the prediction-driven material flow (at the upstream of CODP) and the customer order-driven flow (at the downstream of CODP) [12]. Accordingly, in a value chain, where should CODP be inserted in becomes a crucial issue in determining customization level.

Although there exist many advantages in implementing postponement strategy for manufactures (such as reducing final products inventory, predicting market changes, and decentralizing operational risks), there are still several constraints which were caused by product technology and process, and market characteristics [13]. Postponement strategy requires costly re-designing and the activities of standard components production [14]. No matter if customers choose to customize their expected products, the options they can choose are always limited by some prepared customized parts which makes customers being passive, and to some extent, customers still cannot totally participate in production system and create value for themselves [3].

\subsection{Service-oriented manufacturing}

Nowadays, it is hard to imagine that a manufacturer can still survive by providing pure products without offering some extra services [15]. The growing ambiguity between services and manufacturing industries, especially their implementing boundary, has been reflected in literature about servitization [16], service-dominant logic [17], product-service systems [18], and service-oriented manufacturing [5]. These researches provide some insights into global traditional manufacturing transformation. For example, Grönroos (2008) argued that if manufacturers want to adopt services to obtain competitiveness, it is pivotal for them to identify customers' invisible and potential needs in time. On this basis, integrating tangible products and intangible services into a kind of hybrid offerings for customers can create more value for them [19]. Schmenner (2009) indicated that leading customer to fully involve in the manufacturing and service delivery process is the most effective method to seize customer demands [20]. Wang et al. (2013) pointed out that SOM is a kind of product-service system which outputs hybrid offerings with customer participation, and mutual cooperation between manufacturing and service organizations. Besides, hybrid offerings can realize the value adding in various manufacturing activities of a value chain and benefit related stakeholders [5]. 
The characteristics of SOM include service-based, serviceoriented, and customer interaction [21]. Recently, some scholars have carried out some elaborate studies on this subject, for example, Zhen (2012) discussed the application scope of SOM and pricing compensation [22].

From this literature review, we can see most SOM researchers focused on the concept and framework of postponement strategy and SOM, as well as the benefits of SOM implementation. Despite this, there still exist some limitations, such as research on the management of postponement strategy for SOM and its operations mechanism.

\section{The role of postponement strategy in SOM system}

Make-to-stock (MTS) manufacturers can fulfill customer orders quickly, but are confronted with inventory risks because of short product life cycles and variability in demand. Conversely, make-to-order (MTO) manufacturers can provide various products and fulfill custom orders with lower inventory risks, but most of them have the drawbacks of longer customer lead time [23]. Postponement strategy provides equilibrium between MTS and MTO. Previous literature suggested that implementing postponement strategy could help companies enhance customer knowledge management, and provide better techniques for introducing SOM effectively, especially by positioning CODP. The activities at the upstream of CODP can provide service-oriented manufacturing business to support the work at the downstream, while downstream activities can realize the goal of customizationoriented service business with customer interaction. Ultimately, customer demands would be met and more customer value would be created through the effective integration of upstream and downstream activities of the CODP.

There exist a few key advantages of introducing postponement strategy oriented to SOM. Firstly, as a new advanced manufacturing mode, SOM can help many manufacturers to achieve a successful transition from product-oriented to service-oriented manufacturing, extend traditional manufacturing business, and create more value not only for customers but also for companies. Secondly, SOM alleviates the contradictions between inner manufacturing operation stability and outer market uncertainty. Thirdly, postponement strategy is designed to achieve scale economy based on scope economy. This kind of advantage can not only save cost for businesses but also enable manufacturers to respond customer needs efficiently. Finally, postponement strategy for SOM can reduce operational risks for manufacturers and extend service time, at the same time, promote interaction with customers and reduce inventory backlog. According to the features of SOM, the operations mechanism of postponement strategy for SOM is shown in Fig. 1.
As shown in Fig. 1, in service operation management, manufacturers provide customers with physical products and embedded service and try to divide traditional manufacturing processes into two parts: one with frequent customer communication, another having low customer communication level. Production operation activities with low customer interaction are placed at the upstream of CODP. The main work in this part is to materialize explicit knowledge into standardized components of a product. These components can be regarded as physical carriers for embedded services at the downstream of CODP. All activities here can be collectively called as "service production." The activities with high customer interaction are placed at the downstream of CODP. The purposes of these activities are to achieve a harmony between customer interaction and customization activities, as well as to meet individualized customer needs by mining their tacit requirements. All activities here can be termed as "customized service."

1) Due to the fuzziness, dynamics, diversity, and obscurity of customer demands, the first action that manufacturers should take is conducting an in-depth investigation of customer demands in target markets. Then, they need to make a cluster analysis according to the attributes of distinct customer demands. This work can help manufacturers to derive standardized components from diversified demands. After that, customers can serve themselves by reconstructing expected products through combining standard and individualized components in virtue of modular design, such as the business mode in IKEA.

2) While adopting postponement strategy, manufacturers should place service production activities at the upstream of CODP, because they have the characteristics of low customer interaction, foreseeable varieties, and standard parts. Due to these attributes, manufacturers can combine modularization and standardized parts together to satisfy the customers' basic functional demands, such as the business mode in DELL.

3) At the downstream of CODP, the interactive platform between supply and demand sides is supported by customer participation. The final outputs, that is, hybrid offerings, are customized by customer preferences, which require manufacturers to frequently and deeply communicate with customers.

4) Service production and product-related services can be integrated in the context of SOM. At the upstream of CODP, manufacturers can make full use of the advantages of scale economy and generate service carriers in advance, which can shorten the lead time. At the downstream of CODP, manufacturers can explore tacit knowledge by closely, frequently, and timely interacting with customers, which will make it possible for manufacturers to achieve the goal of scope economy, especially, to extend and customize the relevant service function as well. Ultimately, customer value will be enhanced. 
Fig. 1 Operations mechanism of postponement strategy for SOM

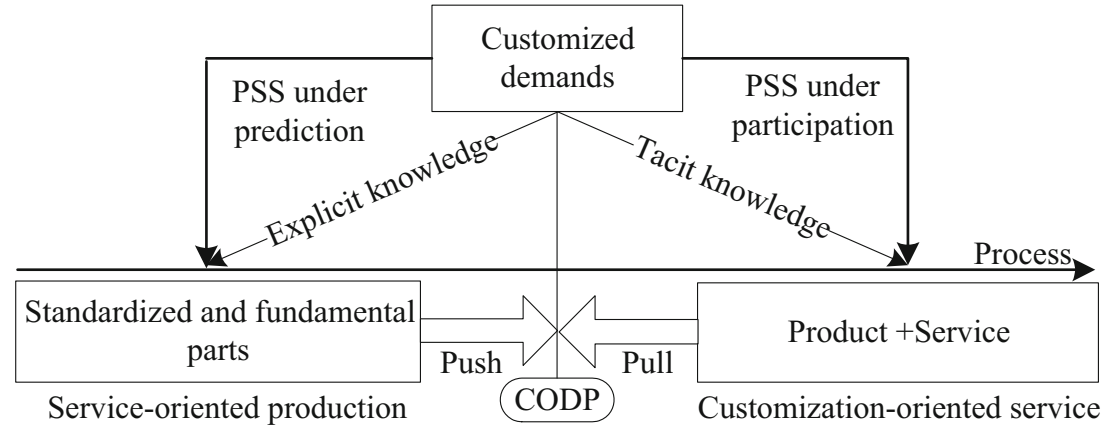

When a manufacturer implements a postponement strategy involving customer interaction, not only it can provide customers with integrated solutions by a specialized productservice bundle, creating value for their customers, but also it can change their roles from "cows seller" to "milk seller," which means manufacturer' profit chain is extended from being one-off sell point to the whole life cycle of a product. Furthermore, the self-service of customers can help manufacturers saving labor costs. In other words, customers will become the members of cooperative producers that would maximize the value of both manufacturers and customers. In conclusion, implementing postponement strategy for SOM enriches the connotation of postponement strategy against its traditional motivation.

\section{A postponement strategy research model}

In order to study the operations mechanism of postponement strategy for SOM, we assume that manufacturers in the market could simultaneously provide two types of products: undifferentiated products (products I) and hybrid products (products II). Products I are produced by the guidance of traditional customer operation mode. Products II (a product-service bundle or hybrid offerings) are generated by the guidance of SOM mode. We also assume that there are only two manufacturers in the market, $P^{M}$ stands for the price of products I, which are always provided by companies $M . P^{S}$ represents the price of products II, which are provided by companies $S\left(P^{S}>P^{M}\right)$. The utility of intangible service varies from person to person, and the evaluation of service from each customer conforms to uniform distribution. Accordingly, $s=0$ represents the minimum benefit that customers can gain from the services and $s=$ 1 indicates the maximum benefit that customer can obtain from the services; thus, the range of $s$ is $0 \leq s \leq 1$. The service provision process usually takes customers a lot of time, because the production and consumption of a certain product cannot be separated from it. $c$ represents the time cost of customer interaction in service customization, and $t$ represents the time cost of service customization. In order to analyze the model more clearly, we suppose that customer's evaluated product I utility is " $B$." For each customer purchasing unit products, the customer utility function $\left(U^{s}\right)$ can be expressed as follows:

$U^{s}=\left\{\begin{array}{l}B-p^{M} \\ B+s^{-}-p^{S}-c\end{array}\right.$

Due to the vertical differences between products II and products I [20], customers are more likely to buy products II if two types of products are offered to the customers at the same price.

Parameters $m(m>0)$ and $w(w>0)$, respectively, represent the unit product cost of products I and the unit service cost of products II $(w>m)$. We assume that $w<2$, because we need to ensure that the market share of each manufacturer is bigger than 0 .

If both of the manufacturers provided products I to the market, due to the product homogeneity, the market is allocated randomly between the two companies under the condition of equal profits. If two companies provided products II to the market, the above situation will be repeated. If one of two manufacturers produced products I and products II, and the sale volume of both their products is greater than 0 , the conditions of market allocation will be as follows: $B+\hat{s}-p^{S}-c=$ $B-p^{M}$, where $\hat{s}$ and $1-\hat{s}$ respectively represent the market share of products I and products II. Therefore, we can obtain the following equations: $\hat{s}=p^{S}-p^{M}+c$ and $1-\hat{s}=1-\left(p^{S}-\right.$ $\left.p^{M}+c\right)$.

The manufactures who provide products I can get profit $\pi^{M}$, which equals $\left(p^{M}-m\right) \hat{s}$, while those who provide products II can get profit $\pi^{S}$, which equals $\left(p^{S}-m-w\right)(1-\hat{s})$. In the equilibrium condition, the product price of one type of manufacturers implementing SOM while others are not doing so can be defined as $\left(\bar{p}^{S}, \bar{p}^{M}\right)$, namely, the manufacturers who produce products I choose the price of $\bar{p}^{M}$ in order to maximize their profits, as function (2) shows, as the same purpose, manufacturers who produce products II would choose the price of $\bar{p}^{S}$, as function (3) shows:

$$
\begin{aligned}
& \pi^{M}=\left(p^{M}-m\right)\left(p^{S}-p^{M}+c\right) \\
& \pi^{S}=\left(p^{S}-m-w\right)\left(1-p^{S}+p^{M}-c\right)
\end{aligned}
$$


The respective derivations of $\bar{p}^{S}$ and $\bar{p}^{M}$ are:

$\frac{d \pi^{M}}{d p^{M}}=p^{S}-2 p^{M}+m+c$
$\frac{d \pi^{S}}{d p^{S}}=1-2 p^{S}+p^{M}+m+w-c$

By equating (4) and (5) to 0, respectively, we obtain the corresponding equilibrium price:

$P^{M}=\frac{1}{2}\left(m+P^{S}+c\right)$

$P^{S}=\frac{1}{2}\left(1+m+w+P^{M}-c\right)$

By associating function (6) and (7), we obtain the results shown in Table 1.

Proposition 1 If $w+c>2$, customers would choose undifferentiated products I.

As shown in Table 1 , when $w+c>2$, the manufacturers providing products II have negative market share. The reason is that the cost of service provision and the input cost of customer participation are too high, which means customer would rather choose undifferentiated products I.

Proposition 2 If $w+c<2$ and companies want to get profit by providing products II, they must primly meet $\bar{\pi}^{S} \geq \bar{\pi}^{M}$, that is, $c \leq \frac{1}{2}-w$.

Proposition 2 can be proved by comparing the profits in Table 1. However, there comes a problem, which is how manufacturers weigh the unit cost of services and the time cost of customer participation when manufacturers provide products II. In this situation, the manufacturers providing products II will increase the unit cost of services $w$, which can minimize customer pre-participation, so that the operation cost would be reduced, service efficiency would be improved and service quality would be ensured. As for customers, participating in service customized system can let them seize a chance for a new experience of product customization and meet their needs as far as possible.

As can be seen from model analysis, the manufacturers cannot respond effectively to customers' customized needs owing to distance and time interval between the supply and demand sides if the manufacturers only provide undifferentiated products I, which is defined as the business of make-to-stock
(MTS). However, if the manufacturers provide products II with close customer participation, which is regarded as the business mode of engineering-to-order (ETO), will extend the delivery time of their product-service bundle due to untimely customer participation and longer service time. Therefore, the method to improve the above two situations is the implementation of postponement strategy for SOM. The specific realization mechanism is that, at the upstream of CODP, manufacturers can provide customers with undifferentiated, common, standard, and module components to reduce operating cost, save operating time, and ensure product quality; at the downstream of CODP, manufacturers can integrate their products and services with customer interaction and provide a heterogeneous productservice bundle for various customers. Accordingly, CODP can be influenced by some factors such as specific demand content of different customers and products structure. Therefore, the issue of our study will be more detailed as, at which stage customer should begin to participate in at the downstream of CODP. To solve this problem, we will further discuss about service time in the next part.

\section{Analysis of model considering service time}

It can be said that if higher the time cost of customer involvement was, the less time customers would spend in service participation and the lower the satisfaction of their customized needs would be. The service time of customer interaction influences not only business income and cost but also the customer satisfaction. Only when manufacturers guided their customer to involve in SOM system, can they optimally allocate companies' resources and paved way for customer new experience.

Manufacturers who introduce postponement to support the business mode of SOM would quickly respond to customized requirement in a low-cost way. Specifically, these manufacturers produce standard parts and organize service model at the upstream of CODP; at the downstream of CODP, they complete the customized requirements with close customer interaction by integrating product and service in hybrid offerings. Only when manufacturers effectively tried to reduce customer interaction unit cost and customer service time, namely, they extended the duration of customer interaction at the downstream of CODP, can customers gain a better experience and greater value creation.

Table 1 Comparison of different types of manufacturers in prices, market share and profits

\begin{tabular}{llll}
\hline $\begin{array}{l}\text { Manufacturer } \\
\text { types }\end{array}$ & Optimal price & Market share & Profits \\
\hline Products I & $\bar{P}^{M}=\frac{1}{3}(1+w+c)+m$ & $\hat{s}=\frac{1}{3}(1+w+c)$ & $\bar{\pi}^{M}=\frac{1}{9}(1+w+c)^{2}$ \\
Products II & $\bar{P}^{S}=\frac{1}{3}(2+2 w-c)+m$ & $1-\hat{s}=1-\frac{1}{3}(1+w+c)$ & $\bar{\pi}^{S}=\frac{1}{9}(2-w-c)^{2}$ \\
\hline
\end{tabular}


In the period of $0 \rightarrow t_{0}$, business activities are located in the initial stage of production. At this time, customer satisfaction is 0 , and customer participation has little significance for improving satisfaction. In the period of $t_{0} \rightarrow t_{1}$, the customers' satisfaction will rise gradually, because within this period, manufacturers try to realize customer requirements by designing customized product and drawing drafts for the expectation of customers with a series of activities of customer interaction. In the period of $t_{1} \rightarrow t_{2}$, manufacturers begin to convert product drafts into physical products, which require the relationship between supply and demand sides to be closer. With customers' involvement increasing and new experiences arising for them, their satisfaction will grow rapidly. From $t_{2}$ to the end of the product life cycle, the customized products will be completed, delivered, and sent customers to use. In this stage, customer satisfaction will increase gradually and approach to $100 \%$ finally. This is because customer have already participated in production customization process from the beginning, which will make them spend less time on learning how to use the product with the help of after-sales services. Adding all this characteristics together, we can find the increasing trend of customer satisfaction in product customization process presenting a first-quick-back-slow state, which is in good agreement with logistic curve. The implementation process of postponement strategy for SOM from time dimension is shown in Fig.2.

In the period of $0 \sim t_{0}$, manufacturers produces standard components or service modules at the upstream of CODP. Activities in this stage belong to service preparation, because they provide service carriers for the activities at the downstream of CODP.

In the period of $t_{0} \sim t_{1}$, manufacturers and customers interact with each other about customized requirements.

In the period of $t_{1} \sim t_{2}$, which can be called buffer period at the downstream of CODP, customers fully express their customized needs, and manufacturers gather and analyze them and try to design specific processes supporting customization.
In the period of $t_{2} \sim t_{3}$, which can be called a stage freezing interactive customization, customers, suppliers and employees participate together in achieving the co-designing of products and services. Furthermore, in this stage, they slightly adjust the relationship between products and services to meet technical permission, and make full use of customer interaction to achieve their customization requirements as far as possible.

According to the above two periods, namely, $t_{1} \sim t_{3}$, with the help of customer interaction, manufacturers guide customers to achieve their customization processes and bring them about series of new service experiences to maximize their value creation. In the period after $t_{3}$, which can be called a stage integrating consumer production and contract services, manufacturers provide standard products and services by establishing contractual relationship to achieve the whole product life cycle services provision.

From the above process analysis, we find that manufacturers introducing SOM should let customers be aware of their real purpose and be participative in product or service customization process, to better meet their needs, as well as obtain customized experiences, finally, create more value for them. However, customers often lack relevant manufacturing knowledge, so manufacturers should improve their ability not only in software but also in hardware, which will facilitate customer to participate in and enhance the possibility to let them learn more in the service product system. Gradually, the roles of customers are changed from being passive receiver to active participator, so that the unit time cost of customer interaction will be reduced and more time for customized service at the downstream of CODP will be saved.

\section{Conclusions}

Being different from the previous literature, this paper firstly researches the operations mechanism of postponement strategy for SOM. Accordingly, the paper compares the profits
Fig. 2 Implementation process of postponement strategy for SOM

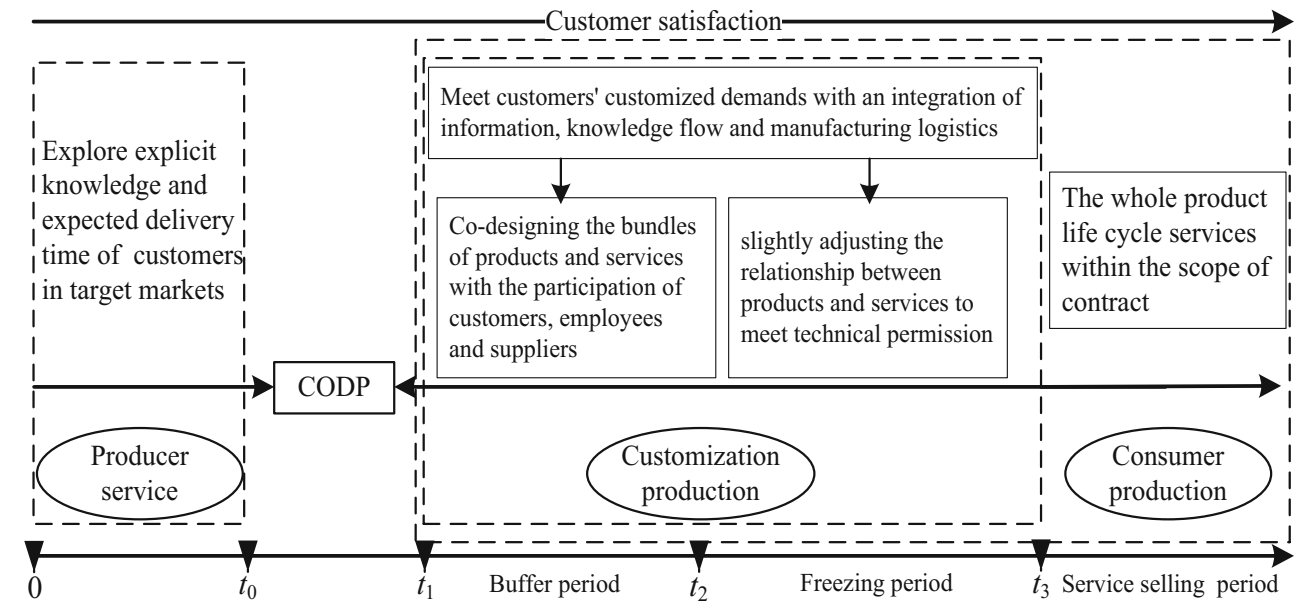


between non-differentiated products and a product-service bundle. Furthermore, by introducing the factor of service time, this paper divides the implementation phase of postponement strategy for SOM into a series of stages. Through above works, we theoretically provide a view about implementing postponement strategy to support manufacturers to transfer into SOM model and better meet heterogeneous customer requirements. There are mainly three key contributions:

Firstly, this study constructed a framework of postponement strategy for SOM and analyzed the basic features respectively of them. Furthermore, from the perspective of customer customized requirements, we research the operations mechanism at the upstream and downstream of CODP.

Secondly, by comparing physical products and hybrid offerings, a product pricing competition model is established. In this model, we analyze the strategy about which kinds of products should be sold for the purpose of maximum profits, and the results help up to better reveal the operations mechanism of postponement strategy for SOM.

Thirdly, our research introduces a new concept, being called customer participation time, in analyzing customizationoriented services and products integrating and provision.

In spite of this paper theoretically provides a new sight of introducing postponement strategy in SOM mode, there are still some limitations: due to the business goals, target markets and the abilities support service provision vary from different industries, manufacturers are still confronting some urgent problems, such as whether they can introduce postponement strategy in their specific SOM system and how to make customer participate in customization processes more effective. As such, there is a lot of room for further research on the topic of postponement strategy for SOM.

Acknowledgements The authors express sincere thanks to the editor(s) and anonymous reviewers of IJAMT for their careful reading and suggestions in improving the quality of this paper.

Funding information The paper is supported by the National Natural Science Foundation of China (Nos. 71772080 and 71472077).

Open Access This article is distributed under the terms of the Creative Commons Attribution 4.0 International License (http:// creativecommons.org/licenses/by/4.0/), which permits unrestricted use, distribution, and reproduction in any medium, provided you give appropriate credit to the original author(s) and the source, provide a link to the Creative Commons license, and indicate if changes were made.

Publisher's Note Springer Nature remains neutral with regard to jurisdictional claims in published maps and institutional affiliations.

\section{References}

1. Ferreira KA, Tomas RN, Alcântara RLC (2015) A theoretical framework for postponement concept in a supply chain. Int J Log Res Appl 18(1):46-61
2. Graman GA (2010) A partial-postponement decision cost model. Eur J Oper Res 201(1):34-44

3. Luo JQ, Zhao YP, Song HM (2010) Implementation mechanism and application of postponement strategy under service-oriented manufacturing environment. Chin Mech Eng 21(22):2693-2698

4. Karmakar U (2004) Will you survive the services revolution? Harv Bus Rev 82(6):100-107

5. Wang K, Jiang Z, Li N, Geng N (2013) Optimal production and admission control for a stochastic SOM system with demands for product and PSS. Int J Prod Res 51(23-24):7270-7288

6. Hobo MS, Watanabe CH, Chen CJ (2006) Double spiral trajectory between retail, manufacturing and customers leads a way to serviceoriented manufacturing. Technovation 26(7):873-890

7. Van Hoek RI (2001) The rediscovery of postponement a literature review and directions for research. J Oper Manag 19(2):161-184

8. Garg A, Tang CS (1997) On postponement strategies for product families with multiple points of differentiation. IIE Trans 29(8): $641-650$

9. Van Hoek RI, Van Dierdonck R (2000) Postponed manufacturing supplementary to transportation services. Transp Res E 36(3):205-217

10. Li J, Wang S, Cheng TCE (2008) Analysis of postponement strategy by EPQ-based models with planned backorders. Omega 36(5): $777-778$

11. Graman GA, Magazine MJ (2002) A numerical analysis of capacitated postponement. Oper Prod Manag 11(3):340-357

12. Zhou W, Zhang R, Zhou Y (2013) A queuing model on supply chain with the form postponement strategy. Comput Ind Eng 66(4):643-652

13. Jeff H, Willem S, Zhou D et al (2007) Postponement strategy from a supply chain perspective: cases from China. Int J Phys Distrib Logist Manag 37(4):331-356

14. Li S, Ragu-Nathan B, Ragu-Nathan TS et al (2004) The impact of supply chain management practices on competitive advantage and organizational performance. Omega 34(2):107-124

15. Baines TS, Lightfoot HW, Benedettini O, Kay JM (2009) The servitization of manufacturing: a review of literature and reflection on future challenges. J Manuf Technol Manag 20(5):547-567

16. Vandermerwe S, Rada J (1988) Servitization of business: adding value by adding services. Eur Manag J 6(4):314-324

17. Vargo SL, Lusch RF (2004) Evolving to a new dominant logic for marketing [J]. J Mark 68(1):1-17

18. Beuren FH, Ferreira MG, Paulo A et al (2013) Product-service systems: a literature review on integrated products and services. J Clean Prod 47(5):222-231

19. Grönroos C (2008) Service logic revisited: who creates value? And who co-creates? Eur Bus Rev 20(4):298-314

20. Schmenner RW (2009) Manufacturing, service, and their integration: some history and theory. Int J Oper Prod Manag 29(5):431-443

21. Gao J, Yao Y, Zhu VC et al (2011) Service-oriented manufacturing: a new product pattern and manufacturing paradigm. J Intell Manuf 22(3):435-446

22. Zhen L (2012) An analytical study on service-oriented manufacturing strategies. Int J Prod Econ 139(1):220-228

23. Hanafy M, Elmaraghy H (2015) Developing assembly line layout for delayed product differentiation using phylogenetic networks. Int J Prod Res 53(9):2633-2651 